\title{
Power Domination Number On Shackle Operation with Points as Lingkage
}

\author{
Ilham Saifudin \\ Informatics Engineering, Faculty of Engineering, Universitas Muhammadiyah Jember, Indonesia \\ ilham.saifudin@unmuhjember.ac.id
}

\begin{tabular}{|c|c|}
\hline & ABSTRACT \\
\hline Article His & $\begin{array}{l}\text { The Power dominating set is a minimum point of determination in a graph that } \\
\text { can dominate the connected dots around it, with a minimum domination point. }\end{array}$ \\
\hline Received : & The smallest cardinality of a power dominating set is called a power domination \\
\hline Revised $1: 01-29-2020$ & number with the notation $\gamma_{n}(G)$. The purpose of this study is to determine the \\
\hline Revised 2 : & Shackle operations graph value from several special graphs with a point as a link. \\
\hline $\begin{array}{ll}\text { Accepted } & : 28-03-20<0 \\
\text { Online } & : 02-04-2020\end{array}$ & The result operation graphs are: Shackle operation graph from Path graph \\
\hline Key & $\begin{array}{l}\text { Shackle operation graph from Star graph Shack }\left(S_{m}, v, n\right) \text {. The method used in } \\
\text { this paper is axiomatic deductive method in solving problems. Understanding the }\end{array}$ \\
\hline $\begin{array}{l}\text { Power Dominating } \\
\text { Number; } \\
\text { Shackle Operation Graph } \\
\text { with Points as Lingkage. }\end{array}$ & $\begin{array}{l}\text { axiomatic method itself is a method of deductive proof principles that applies in } \\
\text { mathematical logic by using theorems that already exist in solving a problem. In } \\
\text { this paper begins by determining the paper object that is the Shackle point } \\
\text { operations result graph. Next determine the cardinality of these graphs. After }\end{array}$ \\
\hline & $\begin{array}{l}\text { that, determine the point that has the maximum degree on the graph as the } \\
\text { dominator point of power domination. Then, check whether the nearest neighbor } \\
\text { has two or more degrees and analyze its optimization by using a ceiling function } \\
\text { comparison between zero forching with the greatest degree of graph. Thus it can } \\
\text { be determined } \Upsilon p \text { minimal and dominated. The results of the power domination } \\
\text { number study on Shackle operation graph result with points as connectors are } \\
\gamma_{p}\left(\operatorname{Shack}\left(P_{m}, v, n\right)\right)=n-1 \text {, for } m \geq 2 \text { and } n \geq 1 ; \gamma_{p}\left(\operatorname{Shack}\left(C_{m}, v, n\right)\right)=n-1 \text {, } \\
\text { for } m \geq 3 \text { and } n \geq 1 ; \gamma_{p}\left(\operatorname{Shack}\left(S_{m}, v, n\right)\right)=n-1 \text {, for } m \geq 3 \text { and } n \geq 1 \text {. }\end{array}$ \\
\hline
\end{tabular}

\section{do) 3 Crossref (c) (i) (2)}

https://doi.org/10.31764/itam.v4i1.1579

This is an open access article under the CC-BY-SA license

\section{A. INTRODUCTION}

Mathematics is very fundamental in the development of science and technology. Almost in all branches of science use mathematics in problem solving. For example, in the fields of science and social sciences. In this case, a topic that is often discussed in the branch of mathematics and at the same time became the forerunner to technological development, namely about Graph Theory.

Graph Theory is one of the subject matter of Discrete Mathematics which has long been known and widely applied in various fields (Munir \& Rinaldi, 2012). In representing the visual of a graph that is by expressing objects with nodes, dots, circles, points, or vertices, while the relationship between objects is expressed by lines or edges (Imelda Roza, Narwen, 2014).

One of the interesting topics in Graph Theory is dominating set. The definition of dominating set is a concept of determining the minimum possible points on a graph by 
determining points as dominating points so that they can reach the points around them (Slamin, Dafik, \& Waspodo, 2018). Dominating set has experienced many developments, such as: locating dominating set, independent dominating set, power dominating set, and others (Zou et al., 2011).

The application of power domination number in daily life, one of them is the placement of LBS (Load Break Switch) on the electrical system that is useful as an electrical circuit breaker. The goal is to make the number of LBS focal points minimal and efficient in their use (Bawono, 2017).

This paper will discuss the power dominating set. Power dominating set is a way to determine the minimum possible points in a graph that can dominate the connected points around it, with the minimum number of dominating points. The smallest cardinality of a power dominating set is called a power domination number with the notation $\gamma_{\mathrm{p}}(\mathrm{G})$ (Benson et al., 2018). To find out the minimum limit of the number of power domination numbers in a graph that is by using the ceiliing function comparison between zero forching with $\mathrm{Z}(\mathrm{G}$ ) notation with the largest degree of a graph (Benson et al., 2015).

Previous studies have investigated Power dominating sets by (Benson et al., 2018), (Chang, Dorbec, Montassier, \& Raspaud, 2012), (Department, 2012), (Dorbec \& Klavžar, 2014), (Ferrero, Hogben, Kenter, \& Young, 2017a), (Stephen, Rajan, Ryan, Grigorious, \& William, 2015), (Seema \& A.Vijayakumar, 2011), (Ferrero, Varghese, \& Vijayakumar, 2011), (Wang, Chen, \& Lu, 2016), (Ferrero, Hogben, Kenter, \& Young, 2017), (Bozeman et al., 2019), and (Dorbec, Henning, Löwenstein, Montassier, \& Raspaud, 2013). The theorem as a reference in this research is Theorem 1: for any graph $\gamma_{p}(G) \geq\left\lceil\frac{Z(G)}{\Delta(G)}\right\rceil$ (Benson et al., 2015). Meanwhile, the graph that will be examined in this research is the Shackle operations result from several special graphs with a point as the link. The operation result graphs are: Shackle operation graph with points as lingkage from Path graph $\operatorname{Shack}\left(P_{m}, v, n\right)$, Shackle operation graph from Cycle graph $\operatorname{Shack}\left(C_{m}, v, n\right)$, Shackle operation graph from $\operatorname{Star} \operatorname{graph} \operatorname{Shack}\left(S_{m}, v, n\right)$. Thus the title can be obtained namely "Power Domination Number on Shackle Operation Graph with Points a Lingkage".

\section{B. METHODS}

The method used in this paper is axiomatic deductive method in solving problems. Understanding the axiomatic method itself is a paper method using the principles of deductive validity proof in mathematical logic by using existing theorems in solving a problem (Lestari, 2015).

In this paper begins by determining the object of the paper that the Shackle point operation result graphs. Next determine the cardinality of these graphs. After that, determine the point that has the maximum degree on the graph as the dominator point of Power Domination. Then, check whether the nearest neighbor has two or more degrees and analyze its optimization by using the comparison of the ceiliing function between zero forching with the largest degree of graph (Yang \& Marzetta, 2013). Thus, it can be determined $\gamma_{p}$ minimal and dominated. 
The graph that will be examined in this research is the Shackle operation result graphs from several special graphs with a point as the link. The operation result graphs are: Shackle operation graph with points as lingkage from Path graph $\operatorname{Shack}\left(P_{m}, v, n\right)$, Shackle operation graph from Cycle graph $\operatorname{Shack}\left(C_{m}, v, n\right)$, Shackle operation graph from Star graph $\operatorname{Shack}\left(S_{m}, v, n\right)$.

\section{RESULTS AND DISCUSSION}

In the results and discussion will be explained about the power dominating number on the Shackle operation result graphs. The results of this paper are several new theorems about power dominating numbers on the Shackle operation result graphs. The initial step in this paper is to determine the cardinality of the Shackle operation result graphs. Then, the second step is to determine the power dominating number on the Shackle operation result graphs. The operation result graphs are: Shackle operation graph with points as lingkage from Path graph $\operatorname{Shack}\left(P_{m}, v, n\right)$, Shackle operation graph from Cycle graph $\operatorname{Shack}\left(C_{m}, v, n\right)$, Shackle operation graph from Star graph $\operatorname{Shack}\left(S_{m}, v, n\right)$. The following are the results of the paper.

\section{Shackle Operation Result Graph From Path Graph}

In this section, the power dominations number theorem on the Shackle operation graph with points as lingkage from the Path graph $\operatorname{Shack}(P, v, n)$ will be presented, followed by theorem evidence. Then an example is given as a visualization of the truth of the theorem.

$\checkmark$ Theorem C.1. For $m \geq 2$ and $n \geq 1$, the power domination number of the graph $\operatorname{Shack}\left(P_{m}, v, n\right)$ is $\gamma_{p}\left(\operatorname{Shack}\left(P_{m}, v, n\right)\right)=n-1$.

\section{Proof.}

Shackle operational result graph from Path graph $\operatorname{Shack}\left(P_{m}, v, n\right)$ is a graph with set point $V$ $\left(\operatorname{Shack}\left(P_{m}, v, n\right)\right)=\left\{A_{i} ; 1 \leq i \leq n\right\} \cup\left\{x_{i j} ; 1 \leq i \leq n-1 ; 1 \leq j \leq m\right\}$ and the set of sides $E\left(\operatorname{Shack}\left(P_{m}, v, n\right)\right)=\left\{A_{i} x_{i j} ; 1 \leq i \leq n-1 ; 1 \leq j \leq m\right\} \cup\left\{A_{i+1} x_{i j} ; 1 \leq i \leq n-1 ; 1 \leq j \leq m\right\}$. So $\quad p=\mid V\left(\operatorname{Shack}\left(P_{m}, v, n\right)|=m n+m+n, q=| E\left(\operatorname{Shack}\left(P_{m}, v, n\right)\right) \mid=3 m n+m-n-1\right.$, $\left|Z\left(\operatorname{Shack}\left(P_{m}, v, n\right)\right)\right|=m n+1$ and $\left|\Delta\left(\operatorname{Shack}\left(P_{m}, v, n\right)\right)\right|=2 m$.

For $m \geq 2$ and $n \geq 1$ it will be shown that $\gamma_{p}\left(\operatorname{Shack}\left(P_{m}, v, n\right)\right) \geq n-1$ by selecting the set of dominator points association that is $S=\left\{A_{i} ; 1 \leq i \leq n\right\}$. Suppose $\gamma_{p}\left(\operatorname{Shack}\left(P_{m}, v, n\right)\right)<$ $n$ by taking $n-2$, then a node will be observed. As an illustration, consider the graph $\operatorname{Shack}\left(P_{m}, v, n\right)$ with $\gamma_{p}\left(\operatorname{Shack}\left(P_{m}, v, n\right)\right)=n-2$. It appears that there are nodes that have more than one neighbor so that the other points are not observed. So the supposition above is wrong then $\gamma_{p}\left(\operatorname{Shack}\left(P_{m}, v, n\right)\right) \geq n-1$.

Next it will be shown that $\gamma_{p}\left(\operatorname{Shack}\left(P_{m}, v, n\right)\right) \leq n-1$ by selecting the set of dominator points association from $\operatorname{Shack}\left(P_{m}, v, n\right)$ which is $S=\left\{A_{i} ; 1 \leq i \leq n\right\}$ which observes other points, then every node in $\left(\operatorname{Shack}\left(P_{m}, v, n\right)\right)$ is observed by $S=\left\{A_{i} ; 1 \leq i \leq n\right\}$, so $\gamma_{p}\left(\operatorname{Shack}\left(P_{m}, v, n\right)\right) \leq|S|=n-1 \quad$. Therefore $\gamma_{p}\left(\operatorname{Shack}\left(P_{m}, v, n\right)\right) \geq n-1 \quad$ and $\gamma_{p}\left(\operatorname{Shack}\left(P_{m}, v, n\right)\right) \leq n-1$, then $\gamma_{p}\left(\operatorname{Shack}\left(P_{m}, v, n\right)\right)=n-1$. The set $S$ containsn elements, namely $S=\left\{A_{i} ; 1 \leq i \leq n\right\}$. Thus the value $\gamma_{p}\left(\operatorname{Shack}\left(P_{m}, v, n\right)\right)=n-1$ is obtained. The following will show an example of graph $\operatorname{Shack}\left(P_{6}, v, 4\right)$ can be seen in Figure 1. 


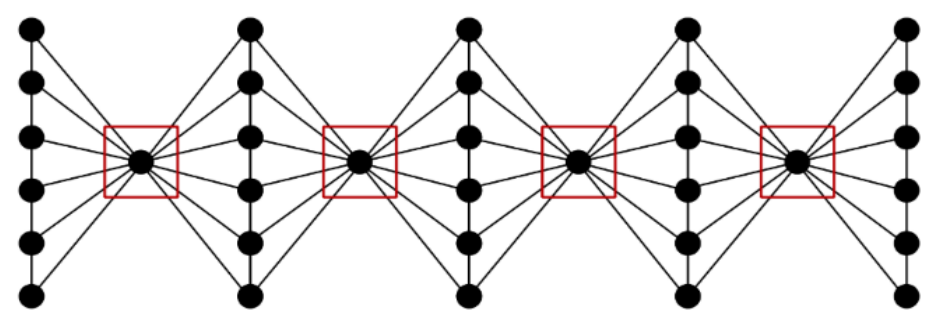

Figure 1. Power Dominating Set Graph $\left(\boldsymbol{S h a c k}\left(\boldsymbol{P}_{\mathbf{6}}, \boldsymbol{v}, \mathbf{4}\right)\right)$

To strengthen the evidence above, based on Theorem 1 , namely $\gamma_{p}(G) \geq\left\lceil\frac{Z(G)}{\Delta(G)}\right\rceil$. It will be shown that $n-1 \geq\left\lceil\frac{m n+1}{2 m}\right\rceil$.

$$
\begin{aligned}
& \gamma_{p}(G) \geq\left\lceil\frac{Z(G)}{\Delta(G)}\right\rceil \\
& n-1 \geq\left\lceil\frac{m n+1}{2 m}\right\rceil \\
& \leftrightarrow n-1 \geq\left\lceil\frac{m n}{2 m}+\frac{1}{2 m}\right\rceil \\
& \leftrightarrow n-1 \geq\left\lceil\frac{m}{2}+\frac{1}{2 m}\right\rceil \\
& \text { Thus } n-1 \geq\left\lceil\frac{m n+1}{2 m}\right\rceil .
\end{aligned}
$$

\section{Shackle Operation Result Graph from Cycle Graph}

In this section, the power dominations number theorem on the Shackle operation graph with points as lingkage from Cycle graph $\operatorname{Shack}\left(C_{m}, v, n\right)$ will be presented, followed by theorem evidence. Then an example is given as a visualization of the theorem truth.

$\diamond$ Theorem C.2. For $m \geq 3$ and $n \geq 1$, the power domination number of the graph $\operatorname{Shack}\left(C_{m}, v, n\right)$ is $\gamma_{p}\left(\operatorname{Shack}\left(C_{m}, v, n\right)\right)=n-1$.

\section{Proof.}

Shackle operational result graph from Cycle Shack $\operatorname{Shack}\left(C_{m}, v, n\right)$ graph is a set of vertices $V\left(\operatorname{Shack}\left(C_{m}, v, n\right)\right)=\left\{A_{i} ; 1 \leq i \leq n\right\} \cup\left\{x_{i j} ; 1 \leq i \leq n-1 ; 1 \leq j \leq m\right\}$ and the set of sides $E\left(\operatorname{Shack}\left(C_{m}, v, n\right)\right)=\left\{A_{i} x_{i j} ; 1 \leq i \leq n-1 ; ; 1 \leq j \leq m\right\} \cup\left\{x_{i j} x_{i j} ; 1 \leq i \leq n-1 ; 1 \leq j \leq m\right\}$. So

$p=\left|V\left(\operatorname{Shack}\left(C_{m}, v, n\right)\right)\right|=m n+m+n, q=\left|E\left(\operatorname{Shack}\left(C_{m}, v, n\right)\right)\right|=3 m n+m, \mid Z(\operatorname{Shac}-$ $\left.k\left(C_{m}, v, n\right)\right) \mid=m n-m+2$ and $\left|\Delta\left(\operatorname{Shack}-\left(C_{m}, v, n\right)\right)\right|=2 m$.

For $m \geq 3$ and $m \geq 1$, it will be shown that $\gamma_{p}\left(\operatorname{Shack}\left(C_{m}, v, n\right)\right) \geq n-1$ by selecting the set of dominator points that is $S=\left\{A_{i} ; 1 \leq i \leq n\right\}$. Suppose $\gamma_{p}\left(\operatorname{Shack}\left(C_{m}, v, n\right)\right)<n-1$ by taking $n-2$, then a node will be observed. As an illustration, consider the graph $\operatorname{Shack}\left(C_{m}, v, n\right)$ with $\gamma_{p}\left(\operatorname{Shack}\left(C_{m}, v, n\right)\right)=n-2$. It appears that there are nodes that have more than one neighbor so that the other points are not observed. So the supposition above is wrong then $\gamma_{p}\left(\operatorname{Shack}\left(C_{m}, v, n\right)\right) \geq n-1$.

Next it will be shown that $\gamma_{p}\left(\operatorname{Shack}\left(C_{m}, v, n\right)\right) \leq n-1$ by selecting the set of dominator points from $\operatorname{Shack}\left(C_{m}, v, n\right)$ which is $S=\left\{A_{i} ; 1 \leq i \leq n\right\}$ which observes other points, then every node in $\left(\operatorname{Shack}\left(C_{m}, v, n\right)\right)$ is observed $S=\left\{A_{i} ; 1 \leq i \leq n\right\}$, so $\gamma_{p}\left(\operatorname{Shack}\left(C_{m}, v, n\right)\right) \leq$ $|S|=n-1$. Therefore $\gamma_{p}\left(\operatorname{Shack}\left(C_{m}, v, n\right)\right) \geq n-1$ and $\gamma_{p}\left(\operatorname{Shack}\left(C_{m}, v, n\right)\right) \leq n-1$, then 
$\gamma_{p}\left(\operatorname{Shack}\left(C_{m}, v, n\right)\right)=n-1$. The set $S$ contains $n-1$ elements namely $S=\left\{A_{i} ; 1 \leq i \leq n\right\}$. Thus the value $\gamma_{p}\left(\operatorname{Shack}\left(C_{m}, v, n\right)\right)=n-1$ is obtained.

To strengthen the evidence above, based on Theorem 1 , namely $\gamma_{p}(G) \geq\left[\frac{Z(G)}{\Delta(G)}\right]$. It will be shown that $n-1 \geq\left\lceil\frac{m n-m+2}{2 m}\right\rceil$.

$$
\begin{aligned}
& \gamma_{p}(G) \geq\left\lceil\frac{Z(G)}{\Delta(G)}\right\rceil \\
& n-1 \geq\left\lceil\frac{m n-m+2}{2 m}\right\rceil \\
& \leftrightarrow n-1 \geq\left\lceil\frac{m n}{2 m}-\frac{m}{2 m}+\frac{2}{2 m}\right\rceil \\
& \leftrightarrow n-1 \geq\left\lceil\frac{n}{2}-\frac{1}{2}+\frac{2}{2 m}\right\rceil \\
& \text { Thus } n-1 \geq\left\lceil\frac{m n-m+2}{2 m}\right\rceil \text {. }
\end{aligned}
$$

The following will show an example of graph $\operatorname{Shack}\left(C_{4}, v, 2\right)$ can be seen in Figure 2.

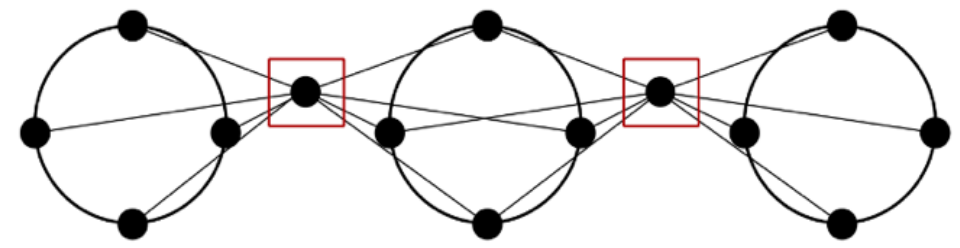

Figure 2. Power Dominating Set Graph $\left(\operatorname{Shack}\left(C_{4}, v, 2\right)\right)$

\section{The Operation Graph from Star Graph}

In this section, the power dominations number theorem on the Shackle operation graph with points as lingkage from the Star graph $\operatorname{Shack}\left(S_{m}, v, n\right)$ will be presented, followed by theorem evidence. Then an example is given as a visualization of the truth of the theorem.

$\diamond$ Theorem C.3. For $m \geq 3$ and $n \geq 1$, the power domination number of the graph $\operatorname{Shack}\left(S_{m}, v, n\right)$ is $\gamma_{p}\left(\operatorname{Shack}\left(S_{m}, v, n\right)\right)=n-1$.

\section{Proof.}

Shackle operation graph from Star graph $\operatorname{Shack}\left(S_{m}, v, n\right)$ is a graph with set point $V\left(\operatorname{Shack}\left(S_{m}, v, n\right)\right)=\left\{A_{i} ; 1 \leq i \leq n\right\} \cup\left\{x_{i j} ; 1 \leq i \leq n-1 ; 1 \leq j \leq m\right\}$ and the set of sides $E\left(\operatorname{Shack}\left(S_{m}, v, n\right)\right)=\left\{A_{i} x_{i j} ; 1 \leq i \leq n-1 ; ; 1 \leq j \leq m\right\} \cup\left\{x_{i j} x_{i j} ; 1 \leq i \leq n-1 ; 1 \leq j \leq\right.$ $m\}$. so $p=\left|V\left(\operatorname{Shack}\left(S_{m}, v, n\right)\right)\right|=m n+m+2 n, q=\left|E\left(\operatorname{Shack}\left(S_{m}, v, n\right)\right)\right|=3 m n+m+$ $2 n,\left|Z\left(\operatorname{Shack}\left(S_{m}, v, n\right)\right)\right|=m n-m+2 m-7$ and $\left|\Delta\left(\operatorname{Shack}\left(S_{m}, v, n\right)\right)\right|=2 m+2$.

For $m \geq 3$ and $m \geq 1$, it will be shown that $\gamma_{p}\left(\operatorname{Shack}\left(S_{m}, v, n\right)\right) \geq n-1$ by selecting the set of dominator points namely $S=\left\{A_{i} ; 1 \leq i \leq n\right\}$. Suppose $\gamma_{p}\left(\operatorname{Shack}\left(S_{m}, v, n\right)\right)<n-1$ by taking $n-2$, then a node will be observed. As an illustration, consider the graph $\operatorname{Shack}\left(S_{m}, v, n\right)$ with $\gamma_{p}\left(\operatorname{Shack}\left(S_{m}, v, n\right)\right)=n-2$. It appears that there are nodes that have more than one neighbor so that the other points are not observed. So the supposition above is wrong then $\gamma_{p}\left(\operatorname{Shack}\left(S_{m}, v, n\right)\right) \geq n-1$.

Next, it will be shown that $\gamma_{p}\left(\operatorname{Shack}\left(S_{m}, v, n\right)\right) \leq n-1$ by selecting the set of dominator points from $\operatorname{Shack}\left(S_{m}, v, n\right)$ yaitu $S=\left\{A_{i} ; 1 \leq i \leq n\right\}$ which observes other points, then every 
node in $\left(\operatorname{Shack}\left(S_{m}, v, n\right)\right)$ is observed by $S=\left\{A_{i} ; 1 \leq i \leq n\right\}$, so $\gamma_{p}\left(\operatorname{Shack}\left(S_{m}, v, n\right)\right) \leq|S|=$ $n-1$. Therefore $\gamma_{p}\left(\operatorname{Shack}\left(S_{m}, v, n\right)\right) \geq n-1$ and $\gamma_{p}\left(\operatorname{Shack}\left(S_{m}, v, n\right)\right) \leq n-1$, then $\gamma_{p}\left(\operatorname{Shack}\left(S_{m}, v, n\right)\right)=n-1$. The set $S$ contains $n-1$ elements namely $S=\left\{A_{i} ; 1 \leq i \leq n\right\}$. Thus the value $\gamma_{p}\left(\operatorname{Shack}\left(S_{m}, v, n\right)\right)=n-1$ is obtained.

To strengthen the evidence above, based on Theorem 1, namely $\gamma_{p}(G) \geq\left\lceil\frac{Z(G)}{\Delta(G)}\right\rceil$. will be shown that $n-1 \geq\left\lceil\frac{m n+n+2 m-7}{2 m+2}\right\rceil$.

$$
\begin{aligned}
& \gamma_{p}(G) \geq\left\lceil\frac{Z(G)}{\Delta(G)}\right\rceil \\
& n-1 \geq\left\lceil\frac{m n+n+2 m-7}{2 m+2}\right\rceil \\
& \leftrightarrow n-1 \geq\left[\frac{n(m+1)+2 m-7}{2(m+1)}\right\rceil \\
& \leftrightarrow n-1 \geq\left\lceil\frac{n(m+1)}{2(m+1)}+\frac{2 m-7}{2 m+2}\right\rceil \\
& \leftrightarrow n-1 \geq\left[\frac{n}{2}+\frac{2 m-7}{2 m+2}\right\rceil \\
& \text { Thus } n-1 \geq\left\lceil\frac{m n+n+2 m-7}{2 m+2}\right\rceil .
\end{aligned}
$$

The following will be shown an example of graphShack $\left(S_{4}, v, 2\right)$ can be seen in Figure 3.

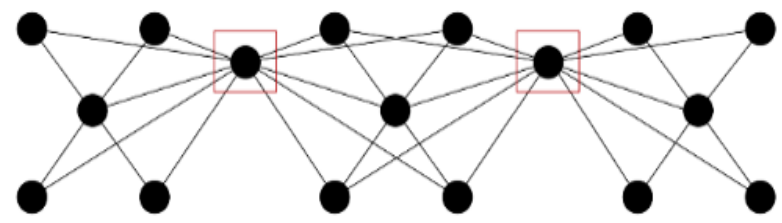

Figure 3. Power Dominating Set $\left(\operatorname{Shack}\left(S_{4}, v, 2\right)\right)$

\section{CONCLUSIONS AND SUGGESTIONS}

The following are conclusions obtained from the results and previous discussions.

1. Cardinalities of points (orders) and sides (sizes) on Shackle operational result graphs with points as lingkage in this paper are as follows:

a. $\left|V\left(\operatorname{Shack}\left(P_{m}, v, n\right)\right)\right|=m n+m+n$ and $\left|E\left(\operatorname{Shack}\left(P_{m}, v, n\right)\right)\right|=3 m n+m-n-1$;

b. $\left|V\left(\operatorname{Shack}\left(C_{m}, v, n\right)\right)\right|=m n+m+n$ and $\left|E\left(\operatorname{Shack}\left(C_{m}, v, n\right)\right)\right|=3 m n+m$;

c. $\left|V\left(\operatorname{Shack}\left(S_{m}, v, n\right)\right)\right|=m n+m+2 n+1$ and $\left|E\left(\operatorname{Shack}\left(S_{m}, v, n\right)\right)\right|=3 m n+m+$ $2 n$.

2. The power domination number on the Shackle operation result with points as lingkage graphs in this paper are as follows:

a. $\gamma_{p}\left(\operatorname{Shack}\left(P_{m}, v, n\right)\right)=n-1$, for $m \geq 2$ and $n \geq 1$;

b. $\gamma_{p}\left(\operatorname{Shack}\left(C_{m}, v, n\right)\right)=n-1$, for $m \geq 3$ and $n \geq 1$;

c. $\gamma_{p}\left(\operatorname{Shack}\left(S_{m}, v, n\right)\right)=n-1$, for $m \geq 3$ and $n \geq 1$;

From the results of the Power Dominating Number research, the researchers provide advice to other researchers to be able to examine the topic with special graphs and other operating results graphs. And can determine applications related to Power Dominating Set to complete solutions in everyday life. 


\section{ACKNOWLEDGEMENT}

The author thanks to Darian Aji Bawono, Jember who inspired the author to conduct research on Power Dominating Numbers from the results of his work with the title Power Dominating Number on Graphs of Side Comb Operational Results with High-Level Thinking Skills.

\section{REFERENCES}

Bawono, D. A. (2017). Power Domination Number Pada Graf Hasil Operasi Comb Sisi Dikaitkan Dengan Keterampilan Berpikir Tingkat Tinggi. Jember: Universitas Jember.

Benson, K. F., Ferrero, D., Flagg, M., Furst, V., Hogben, L., Vasilevska, V., \& Wissman, B. (2015). Power domination and zero forcing. 1-10.

Benson, K. F., Ferrero, D., Flagg, M., Furst, V., Hogben, L., Vasilevska, V., \& Wissman, B. (2018). Zero forcing and power domination for graph products. Australasian Journal of Combinatorics, 70(2), 221-235.

Bozeman, C., Brimkov, B., Erickson, C., Ferrero, D., Flagg, M., \& Hogben, L. (2019). Restricted power domination and zero forcing problems. Journal of Combinatorial Optimization, 37(3), 935-956. https://doi.org/10.1007/s10878-018-0330-6

Chang, G. J., Dorbec, P., Montassier, M., \& Raspaud, A. (2012). Generalized power domination of graphs. Discrete Applied Mathematics, 160(12), 1691-1698. https://doi.org/10.1016/j.dam.2012.03.007

Department, J. S. (2012). Deception Tactics for Network Interdiction: A Multiobjective Approach. Networks, 60(1), 45-58. https://doi.org/10.1002/net

Dorbec, P., Henning, M. A., Löwenstein, C., Montassier, M., \& Raspaud, A. (2013). Generalized power domination in regular graphs. SIAM Journal on Discrete Mathematics, 27(3), 1559-1574. https://doi.org/10.1137/120891356

Dorbec, P., \& Klavžar, S. (2014). Generalized Power Domination: Propagation Radius and Sierpiński Graphs. Acta Applicandae Mathematicae, 134(1), 75-86. https://doi.org/10.1007/s10440-0149870-7

Ferrero, D., Hogben, L., Kenter, F. H. J., \& Young, M. (2017a). Note on power propagation time and lower bounds for the power domination number. Journal of Combinatorial Optimization, 34(3), 736-741. https://doi.org/10.1007/s10878-016-0103-z

Ferrero, D., Hogben, L., Kenter, F. H. J., \& Young, M. (2017b). The relationship between $\$ k \$$-forcing and $\$ k \$$-power domination. 1-15.

Ferrero, D., Varghese, S., \& Vijayakumar, A. (2011). Power domination in honeycomb networks. Journal of Discrete Mathematical Sciences and Cryptography, 14(6), 521-529. https://doi.org/10.1080/09720529.2011.10698353

Imelda Roza, Narwen, Z. (2014). Graf Garis (Line Graph) dari Graf Siklus, Graf Lengkap dan Graf Bintang. Jurnal Matematika UNAND, 3(2), 2-5.

Lestari, K. E. (2015). Analisis Kemampuan Pembuktian Matematis Mahasiswa Menggunakan Pendekatan Induktif-Deduktif Pada Mata Kuliah Analisis Real. MENDIDIK: Jurnal Kajian Pendidikan Dan Pengajaran, 1(2), 128-135.

Munir, \& Rinaldi. (2012). Matematika Diskrit. Bandung: Departemen Teknik Informatika Institut Teknologi Bandung.

Seema, V., \& A.Vijayakumar. (2011). Power domination in some classes of graphs. EuroComb'11, 15(2), 80-89.

Slamin, Dafik, \& Waspodo, G. A. (2018). Distance Domination Number of Graphs Resulting from Edge Comb Product. Journal of Physics: Conference Series, 1022(1). https://doi.org/10.1088/17426596/1022/1/012008

Stephen, S., Rajan, B., Ryan, J., Grigorious, C., \& William, A. (2015). Power domination in certain chemical structures. Journal of Discrete Algorithms, 33, 10-18. https://doi.org/10.1016/j.jda.2014.12.003

Wang, C., Chen, L., \& Lu, C. (2016). k-Power domination in block graphs. Journal of Combinatorial Optimization, 31(2), 865-873. https://doi.org/10.1007/s10878-014-9795-0

Yang, H., \& Marzetta, T. L. (2013). Performance of conjugate and zero-forcing beamforming in large- 
8 | JTAM (Jurnal Teori dan Aplikasi Matematika) | Vol. 4, No. 1, April 2020, pp. 1-8

scale antenna systems. IEEE Journal on Selected Areas in Communications, 31(2), 172-179. https://doi.org/10.1109/JSAC.2013.130206

Zou, F., Wang, Y., Xu, X. H., Li, X., Du, H., Wan, P., \& Wu, W. (2011). New approximations for minimumweighted dominating sets and minimum-weighted connected dominating sets on unit disk graphs. Theoretical Computer Science, 412(3), 198-208. https://doi.org/10.1016/j.tcs.2009.06.022 